\title{
Introduction to the special issue on the 2018 Hualien, Taiwan, earthquake
}

\author{
Ruey-Juin Rau ${ }^{1, *}$ and Tai-Lin Tseng ${ }^{2}$ \\ ${ }^{I}$ Department of Earth Sciences, National Cheng Kung University, Tainan City, Taiwan \\ ${ }^{2}$ Department of Geosciences, National Taiwan University, Taipei City, Taiwan
}

Received 29 May 2019, Accepted 31 May 2019

Keywords: 2018 Hualien earthquake

Citation: Rau, R.-J.and T.-L. Tseng, 2019: Introduction to the special issue on the 2018 Hualien, Taiwan, earthquake. Terr. Atmos. Ocean. Sci., 30, 281-283, doi: 10.3319/TAO.2019.05.31.01

Exactly two years after the $2016 \mathrm{M}_{\mathrm{w}} 6.5$ Meinong event, an $\mathrm{M}_{\mathrm{w}} 6.4$ earthquake occurred slightly offshore Hualien at about $16 \mathrm{~km}$ NNE of the Hualien city with a focal depth of $6.3 \mathrm{~km}$ on 6 February 2018 (23:50:41.6 local time). It is a moderate-sized event, however, produced strong shaking in the Hualien city, triggered and ruptured the Milun fault, which was previously activated during the $1951 \mathrm{M}$ 7.3 Hualien-Taitung earthquake sequence (e.g., Chen et al. 2008). The 2018 event caused several buildings along the Milun fault collapsed and 17 deaths. At the end of 2015, the Taiwan Earthquake Model (TEM) announced a seismic hazard map of Taiwan indicating a relatively high seismic hazard in both Tainan and Hualien (Rau and Ma 2016; Wang et al. 2016). The occurrences of the 2016 Meinong event and the 2018 Hualien event validate and strengthen the importance of the seismic hazard map proposed by TEM (Rau and Liang 2017). With the extremely high strain rate, $10^{-7}-10^{-6}$, and therefore short earthquake recurrence intervals in Taiwan, reactivations of any pre-existing structures in this highly deformed crust are immensely anticipated in the foreseeable future.

The 6 February 2018 Hualien earthquake main shock $\left(M_{w}\right.$ 6.4) was preceded by prominent foreshocks, which considerably overlapped with the 4 February $\left(M_{w} 6.1\right)$ earthquake sequence in the offshore region northeast of Hualien city. The close distribution in space and time between the two sequences had made it difficult to clearly define their relation, whereas the overall length of the foreshocksmainshock-aftershocks sequence is approximately $50 \mathrm{~km}$ with complicated rupture. For the special issue of this 2018 Hualien event, we have collected 13 papers focused on field investigations, GPS and InSAR analyses, rupture models, seismicity, earthquake early warning, and integrated geophysical observations. The research presented here provide valuable constrains to the rupture behavior and geologic

\footnotetext{
* Corresponding author

E-mail:raurj@mail.ncku.edu.tw
}

structures in the region. It is also an important and yet a great challenge to evaluate the forecast models based on precursory events or foreshock-aftershock properties.

To begin with Tung et al. (2019) determined the coseismic deformation of the 2018 Hualien event using the continuous GPS measurements and InSAR analyses and they found that the main deformation is concentrated on the Milun and the Lingding faults. Moreover, they suggested that an unknown west-dipping fault close to the Lingding fault was triggered during the earthquake sequence. Tung et al. (2019) also obtained 1-Hz GPS positions peak ground displacement to evaluate the earthquake damages of the Hualien area. Wu et al. (2019), on the other hand, investigated and re-measured more than 100 benchmarks set up by various agencies by using network RTK. They found 70 and $50 \mathrm{~cm}$ coseismic left-lateral motion for the Milun and the Lingding faults, respectively, yet the Milun Terrace showing uplifting motion and the northern Coastal Range indicating subsidence.

Three studies focused on field investigations of the surface coseismic ruptures using field geology, stress analyses and unmanned aerial systems photogrammetry. Huang et al. (2019) investigated the coseismic rupture patterns of the 2018 Hualien earthquake using the analyses from field survey and drone-based image results. They found that major ruptures occurred as arrays of Riedel shears and formed right-stepping step-overs and restraining bends in the linking damage zones along the Milun fault, where the rupture traces repeat the surface breaks of the 1951 M 7.3 Hualien-Taitung earthquake sequence. Characteristics of the 2018 coseismic ruptures apparently closely related to the near-surface geology structure along the Milun fault and such features provide important information for earthquake hazard assessment on this extremely active Milun fault in eastern Taiwan.

Independently Hsu et al. (2019) conducted field surveys along the Milun fault and examined the coseismic ruptures of the 2018 Hualien event. In addition to the rupture geometry, they determined the principal displacement zone and 
the regional stress directions of the surface ruptures. They suggested that the coseismic rupture forms a horsetail structure at Qixingtan in the northernmost part of the Milun fault, and a fault splays trending $170^{\circ}$ in the central segments. The coseismic surface rupture of the Milun fault and the surface trace of the Beipu fault to its left form a macro-scale Riedel shear model with a maximum horizontal compressive stress directing NW-SE. Results of this study offer an extraordinary example to understand the linkage between the outcrop scale and the macro-scale of the Riedel shear model.

Lin et al. (2019) used the unmanned aerial systems photogrammetry to collect aerial images and to map surface fractures of the 2018 Hualien event. They showed that surface ruptures follow the traces of the Milun fault and northern Linding fault. The mapped surface ruptures are typically appeared in en échelon arrays or distributed fractures rather than a through-going fault, which are comparable to the results of Hsu et al. (2019) and Huang et al. (2019). They considered that the appearances of the along-strike variations of the surface rupture for the 2018 Hualien earthquake are different from the surface rupture patterns documented for the 1951 Hualien-Taitung event.

For the earthquake source model, Hwang et al. (2019) conducted a simple forward analysis to constrain the rupture of the main shock of 2018 Hualien earthquake, which can be decomposed into six sub-events with the maximum moment rate at $6.9 \mathrm{~s}$ and the focal depth is $9 \mathrm{~km}$. Along the west-dipping fault, the overall duration and velocity of rupture are $\sim 11 \mathrm{~s}$ and $<2.0 \mathrm{~km} \mathrm{~s}^{-1}(\sim 0.6 \mathrm{Vs})$, respectively. The total fault length derived from moment (Mo) is about $\sim 21 \mathrm{~km}$. Two stages of rupture are proposed with the changes on stress drop $(\Delta \sigma s)$, energy moment ratio (Es/Mo) and speed across the sea-land boundary. The results are comparable to other source studies (e.g., Jian et al. 2019; Wen et al. 2019b).

In Wen et al. (2019b), multi-segment rupture is constrained by finite fault inversion of far-field seismic data and forward modeling of local GPS deformation. The preferred model consists of two fault planes: a west-dipping main fault dominant in the initial rupture and a shallow eastdipping fault taken over in the later phase, with a rupture speed of $2 \mathrm{~km} \mathrm{~s}^{-1}$. After examining the possible trade-off and ambiguities in solutions, the results show that the main asperity, with strong left-lateral slip, is right underneath Milun Fault where the major damage and the centroid location of regional moment tensor located.

Wen et al. (2019a) focused on the local background structure of the region and its relation with the 2018 Hualien earthquake. This article presents a comprehensive seismological analysis including 3-D tomographic inversion, earthquake relocation, and focal mechanism determination in the Hualien region. A concentration of low velocity and high $\mathrm{Vp} / \mathrm{Vs}$ is found at shallow depth near Meilun fault which could be passively ruptured (Wen et al. 2019b). On the contrary, high $\mathrm{Vp}$ and low $\mathrm{Vp} / \mathrm{Vs}$ appear at deeper depth on a west dipping seismic zone further north where the 2018 event initiated. The high $\mathrm{Vp} / \mathrm{Vs} \&$ seismicity is interpreted as the presence of migrating fluid. The low velocity near Meilun seems correlated well with the drop of rupture speed observed by other studies (Hwang et al. 2019).

Two studies concern the seismicity rate of the Hualien sequences that are related to the hazard potential. Chen et al. (2019c) explored the temporal evolution of the 2018 Hualien earthquake sequence and other major events previous occurred in the nearby region based on the CWB seismicity catalogues. For both foreshocks and aftershocks of the 2018 Haulien sequence, the seismicity rates (K-values) are relatively high among all 11 studied events, while the b-values are almost the lowest $(0.63$ and 0.68$)$, which is also significantly below the long term background average (0.99). Comparisons lead to the conclusions that the high seismicity rate accompanied with a low b-values is indicative of higher potential for events with larger magnitude.

Chen et al. (2019d) estimated "time-varying" b-values and seismicity rates after the Hualien main shock based on generalized Reasenberg-Jones statistic models. The study attempt to forecast, in near real-time manner, the forthcoming aftershock hazard based on 6- and 12-hr windows after the main shock. They found the double-sequence model, which comprise main shock and the second large aftershock (M 5.4 on 7 February), can better predict the aftershock occurrence rate with magnitude above 3 . It not only shows the improvements on short-term hazard evaluation but also independently supports the multi-sequence nature of the 2018 Hualien earthquake. This study also confirmed the low bvalue obtained in $72 \mathrm{hr}$ after Hualien main shock in Chen et al. (2019c).

Chen et al. (2019b) demonstrates the efficiency of the CWB Early Warning System on the 2018 Hualien earthquake sequence. The study implemented the "effective epicenter," a new approach based on triggered stations to estimate intensity. The results show that the time for issuance warning can be shortened by $2-9$ s, comparing with the original system. The improvement on the prediction of maximum intensity is however less satisfying because the values predicted for the event sequences are generally underestimated with respect to the actual observations. Furthermore, Chang et al. (2019) presented a new method to automatically identify $\mathrm{P}$ and $\mathrm{S}$ phases and therefore the event detection, with an algorithm computationally efficient and suitable for the high seismicity rate of the dense seismic network in Taiwan. The algorithm was applied near real-time to the foreshockmainshock sequences of the 2018 Hualien earthquake, and proven to provide timely information for the estimation of seismic hazard assessment and source characteristics.

Finally, Chen et al. (2019a) reported coseismic data of the 2018 Hualien earthquake observed from the induction magnetometers, geophones, infrasound systems, tiltmeters, micro-barometers, and fluxgate magnetometers established 
in Taiwan. Long-lasting coseismic geomagnetic fluctuations were recorded by both induction and fluxgate magnetometers, and about 15 - $45 \mathrm{~s}$ delayed seismo-traveling atmospheric disturbances were observed in infrasonic waves and micro-barometers. The long-lasting coseismic geomagnetic fluctuations are likely resulted from the interaction of surface waves and groundwater oscillations.

Acknowledgements We wish to thank all the authors who contributed to this special issue and we express our gratitude to many reviewers who provided thorough and insightful comments to the manuscripts. This preface was supported by Ministry of Science and Technology under grants MOST 108-2119-M-006-004.

\section{REFERENCES}

Chang, Y.-H., S.-H. Hung, and Y.-L. Chen, 2019: A fast algorithm for automatic phase picker and event location: Application to the 2018 Hualien earthquake sequences. Terr. Atmos. Ocean. Sci., 30, 435-448, doi: 10.3319/ TAO.2018.12.23.01. [Link]

Chen, C.-R., J.-Y. Liu, C.-H. Chen, T.-Y. Wu, H.-Y. Yen, S. Wen, B.-S. Huang, C.-H. Lin, C.-M. Lin, and H.H. Hsieh, 2019a: Co-seismic geomagnetic fluctuations and atmospheric disturbances during the 2018 M 6.2 Hualien earthquake. Terr. Atmos. Ocean. Sci., 30, 449465, doi: 10.3319/TAO.2019.03.11.01. [Link]

Chen, D.-Y., T.-L. Lin, H.-C. Hsu, Y.-C. Hsu, and N.-C. Hsiao, 2019b: An approach to improve the performance of the earthquake early warning system for the 2018 Hualien earthquake in Taiwan. Terr. Atmos. Ocean. Sci., 30, 423-433, doi: 10.3319/TAO.2018.12.23.02. [Link]

Chen, K. H., S. Toda, and R.-J. Rau, 2008: A leaping, triggered sequence along a segmented fault: The 1951 $M_{L} 7.3$ Hualien-Taitung earthquake sequence in eastern Taiwan. J. Geophys. Res., 113, B02304, doi: 10.1029/2007JB005048. [Link]

Chen, P.-F., Y.-L. Chen, P.-L. Su, Y.-D. Peng, and L.-F. Chen, 2019c: Understanding the 6 February 2018, Hualien earthquake sequence through catalog compilation. Terr. Atmos. Ocean. Sci., 30, 399-409, doi: 10.3319/TAO.2018.11.15.02. [Link]

Chen, Y.-I., J.-Y. Liu, and Z.-S. Jian, 2019d: Evaluation of aftershock hazard of the 2018 M 6.2 Hualien earthquake. Terr. Atmos. Ocean. Sci., 30, 411-421, doi: 10.3319/TAO.2018.12.09.01. [Link]

Hsu, Y.-C., C.-P. Chang, J.-Y. Yen, H. Kuo-Chen, and C.C. Wang, 2019: Investigating the structure of the Milun Fault from surface ruptures of the 2018 Hualien Earthquake. Terr. Atmos. Ocean. Sci., 30, 337-350, doi: 10.3319/TAO.2018.09.28.01. [Link]
Huang, S.-Y., J.-Y. Yen, B.-L. Wu, I.-C. Yen, and R. Y. Chuang, 2019: Investigating the Milun Fault: The coseismic surface rupture zone of the 2018/02/06 $\mathrm{M}_{\mathrm{L}} 6.2$ Hualien earthquake, Taiwan. Terr. Atmos. Ocean. Sci., 30, 311-335, doi: 10.3319/TAO.2018.12.09.03. [Link]

Hwang, R.-D., C.-Y. Lin, C.-Y. Lin, W.-Y. Chang, T.-W. Lin, Y.-L. Huang, and J.-P. Chang, 2019: Multipleevent analysis of the $2018 \mathrm{M}_{\mathrm{L}} 6.2$ Hualien earthquake using source time functions. Terr. Atmos. Ocean. Sci., 30, 367-376, doi: 10.3319/TAO.2018.11.15.01. [Link]

Jian, P.-R., S.-H. Hung, and L. Meng, 2019: Rupture behavior and interaction of the 2018 Hualien earthquake sequence and its tectonic implication. Seismol. Res. Lett., 90, 68-77, doi: 10.1785/0220180241. [Link]

Lin, Y.-S., R. Y. Chuang, J.-Y. Yen, Y.-C. Chen, Y.-T. Kuo, B.-L. Wu, S.-Y. Huang, and C.-J. Yang, 2019: Mapping surface breakages of the 2018 Hualien earthquake by using UAS photogrammetry. Terr. Atmos. Ocean. Sci., 30, 351-366, doi: 10.3319/TAO.2018.12.09.02. [Link]

Rau, R.-J. and W.-T. Liang, 2017: Introduction to the special issue on the 2016 Meinong, Taiwan, earthquake. Terr. Atmos. Ocean. Sci., 28, I-III, doi: 10.3319/ TAO.2017.06.07.01. [Link]

Rau, R.-J. and K.-F. Ma, 2016: Preface to the special issue on "Taiwan Earthquake Model: Seismic hazard assessment and earthquake scenario". Terr. Atmos. Ocean. Sci., 27, I-III, doi: 10.3319/TAO.2016.06.01.01(TEM). [Link]

Tung, H., H.-Y. Chen, Y.-J. Hsu, J.-C. Hu, Y.-H. Chang, and Y.-T. Kuo, 2019: Triggered slip on multifaults after the $2018 \mathrm{M}_{\mathrm{w}} 6.4$ Hualien earthquake by continuous GPS and InSAR measurements. Terr. Atmos. Ocean. Sci., 30, 285-300, doi: 10.3319/TAO.2019.04.03.01. [Link]

Wang, Y.-J., C.-H. Chan, Y.-T. Lee, K.-F. Ma, J. B. H. Shyu, R.-J. Rau, and C.-T. Cheng, 2016: Probabilistic seismic hazard assessment for Taiwan. Terr. Atmos. Ocean. Sci., 27, 325-340, doi: 10.3319/ TAO.2016.05.03.01(TEM). [Link]

Wen, S., Y.-Y. Wen, K.-E. Ching, Y.-L. Yeh, and Y.-H. Lee, 2019a: Tectonic implications on the 2018 Hualien Earthquake. Terr. Atmos. Ocean. Sci., 30, 389-398, doi: 10.3319/TAO.2019.01.28.01. [Link]

Wen, Y.-Y., S. Wen, Y.-H. Lee, and K.-E. Ching, 2019b: The kinematic source analysis for $2018 \mathrm{M}_{\mathrm{w}} 6.4$ Hualien, Taiwan earthquake. Terr. Atmos. Ocean. Sci., 30, 377-387, doi: 10.3319/TAO.2018.11.15.03. [Link]

Wu, B.-L., J.-Y. Yen, S.-Y. Huang, Y.-T. Kuo, and W.Y. Chang, 2019: Surface deformation of 0206 Hualien earthquake revealed by the integrated network of RTK GPS. Terr. Atmos. Ocean. Sci., 30, 301-310, doi: 10.3319/TAO.2019.05.27.01. [Link] 